\title{
Hawksbill turtle monitoring in Cousin Island Special Reserve, Seychelles: an eight-fold increase in annual nesting numbers
}

\author{
Zoë C. Allen ${ }^{1, *}$, Nirmal J. Shah ${ }^{1}$, Alastair Grant ${ }^{2}$, Gilles-David Derand $^{1}{ }_{\text {, Diana Bell }}{ }^{2}$ \\ ${ }^{1}$ Nature Seychelles, PO Box 1310, The Centre for Environment \& Education, Roche Caiman, Mahe, Seychelles \\ ${ }^{2}$ School of Biological Sciences, University of East Anglia, Norwich, Norfolk NR4 7TJ, UK
}

\begin{abstract}
Results of hawksbill turtle Eretmochelys imbricata nest monitoring on Cousin Island, Seychelles, indicate an 8-fold increase in abundance of nesting females since the early 1970s when the population was highly depleted. From 1999 to 2009, the population increased at an average rate of 16.5 turtles per season. Females were individually tagged, and nesting data were derived from indirect evidence of nesting attempts (i.e. tracks) and actual turtle sightings (56 to $60 \%$ of all encounters). Survey effort varied over the years for a variety of reasons, but the underlying trends over time are considered robust. To overcome biases associated with variable survey effort, we estimated population changes by fitting a Poisson distribution to data on numbers of times each individual was seen at this breeding site in a season. This was used to estimate unseen individuals, and hence the total number of nesting females each season. The maximum number of individuals emerging onto Cousin Island to nest within a single season was estimated to be 256 (2007 to 2008) compared to 23 in 1973. Tag returns indicate that many turtles nest on both Cousin and Cousine Islands ( $2 \mathrm{~km}$ apart), and that some inter-island nesting also occurs between Cousin and more remote islands within the Seychelles.
\end{abstract}

KEY WORDS: Eretmochelys imbricata $\cdot$ Indian Ocean $\cdot$ Seychelles $\cdot$ Turtle conservation

\section{INTRODUCTION}

Hawksbill turtles Eretmochelys imbricata were listed as Endangered by the IUCN up until 1996 and Critically Endangered from 1996 onwards (Mortimer \& Donnelly 2008) as the worldwide population suffered dramatic declines due to international trade in their raw shell (Mortimer \& Collie 1998). A ban on international trade has since been imposed, but problems of by-catch and habitat destruction still remain in some countries (Meylan \& Donnelly 1999). At the national level, the status of hawksbill turtles varies greatly between regions and is dependent on a number of factors, including intensity of past harvesting, implementation and enforcement of effective conservation measures, local population dynamics, including growth rate and age to maturity, and migration of turtles across international boundaries (Mortimer 1996, 2000).
Turtle populations are notoriously difficult to census, relying upon long-term monitoring of females at their nesting beaches (Meylan \& Donnelly 1999), and comprehensive monitoring tends to be established at sites where hawksbill turtles are well protected rather than randomly distributed throughout their range. The available data indicate that the largest remaining populations of hawksbills occur around Australia, Mexico and the Seychelles, where the breeding populations are estimated to be in the thousands (Meylan \& Donnelly 1999).

The Seychelles comprise an archipelago of 115 islands northeast of Madagascar in the western Indian Ocean. Hawksbill turtles can be found throughout the Seychelles, with the main concentrations on the granitic islands and the sandy cay islands. The Seychelles population was particularly vulnerable to harvesting and disturbance, as these turtles typically nest during 
the day (Mortimer \& Collie 1998), and the threat of disturbance remains on beaches with public access. The harvesting of hawksbills continued for more than 2 centuries, with an estimated $82950 \mathrm{~kg}$ of raw shell exported between 1894 and 1982 (Mortimer 1984). In 1994, however, hawksbill turtles gained complete legal protection, which is generally well enforced on most of the islands (Mortimer \& Collie 1998). Today, the Seychelles provide important nesting and feeding areas for hawksbill turtles and are home to the largest remaining populations within the western Indian Ocean (Mortimer 1984). This is partly due to the fact that the Seychelles were not colonised by humans until 1770 (Mortimer \& Collie 1998), but may also be related to evidence indicating that many turtles in this population remain resident around the protected Seychelles region throughout their adult life (Mortimer \& Balazs 1999).

Cousin Island has been managed as a Special Reserve since 1968, and management was transferred to Nature Seychelles in 1998 (Mortimer \& Bresson 1999). It is inhabited only by the wardens who protect the reserve, and at $29 \mathrm{ha}$, it is one of the smaller islands within the granitic Seychelles yet one of the most important nesting grounds within this region (Diamond 1976). Cousin has a monitoring programme dating back to 1970, making it one of the longest running worldwide (Mortimer \& Bresson 1994). From 1973 to 1975, the estimated number of breeding turtles per season was between 23 and 27 with 80 to 116 nests laid (Diamond 1976). Between 1981 and 1983, an estimated 28-30 turtles were breeding each season, with around 80-100 nests being produced (Wood 1986) and, by 1994, this had increased to 40-60 nesting turtles per season, with around 220 nests being laid during the
1991-1992 season (Mortimer \& Bresson 1994). Here we report the trend in numbers of nesting female turtles and their inter-island movements between 1999 and 2009.

\section{MATERIALS AND METHODS}

Study site. There are 5 beaches on Cousin Island (Fig. 1), and all are used by hawksbill turtles. These are, from the NW side working clockwise, Anse Vacoa (length $67 \mathrm{~m})$, Main Beach $(1.4 \mathrm{~km})$, Twin Beaches $(51.3 \mathrm{~m})$, Anse Saline $(8.3 \mathrm{~m})$ and Anse Frégate $(154 \mathrm{~m})$. Each beach is separated by a natural wall of rocks that prevents turtles from emerging in these areas. Main Beach is divided into $50 \mathrm{~m}$ sections, marked by poles with the letters $A-Z$, to allow precise recording of turtle nest locations. One important seasonal feature is the dramatic change in beach profile, as the sand is highly mobile (Hill et al. 2002). Two main seasons occur in the Seychelles: the northwest monsoon (November to April), which brings hot weather and heavy rainfall, and the southeast trade winds (May to October), which are cooler and drier. During the northwest monsoon, sand is shifted towards Anse Saline, and during the southeast trade winds, it shifts back towards Anse Vacoa (Diamond 1976). The movement of sand from an area can uncover part of the reef, which subsequently becomes exposed during low tide. Although these rocky areas do not generally create a barrier to turtles emerging from the water, they can make nesting almost impossible in places where there is only a thin layer of sand on top. The Seychelles experience mixed semidiurnal tides (Taylor 1968), consisting of 2 low and 2 high tides of different heights within

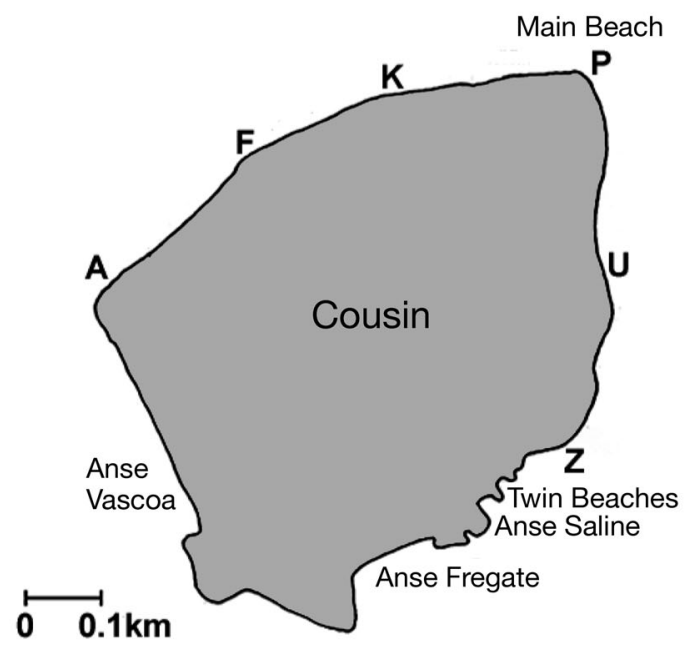

Fig. 1. Cousin Island ( $4^{\circ} 19^{\prime} \mathrm{S}, 55^{\circ} 39^{\prime} \mathrm{E}$ ), showing the beaches and divisions of the Main Beach (adapted from a Nature Seychelles map with permission). Main Beach is divided into $50 \mathrm{~m}$ sections, marked by poles with the letters A-Z, to allow precise recording of turtle nest locations. Inset: location of Cousin Island within the Seychelles archipelago 
each $24 \mathrm{~h}$ period. The tidal range is narrow, around $1.8 \mathrm{~m}$ at spring tides and $1.4 \mathrm{~m}$ at neap tides, and does not appear to affect turtle emergences (Diamond 1976).

Hawksbill turtle nesting. On Cousin Island, hawksbill turtles emerge during the northwest monsoon and thus the nesting 'season' spans from August to March each year. Within the Seychelles, hawksbills typically, and unusually for this species, nest diurnally.

Turtle monitoring. Consistent turtle monitoring commenced each season when wardens observed the first evidence of a turtle emerging onto the beach to lay her nest. This generally occurred around late August, and turtles continued to emerge until late February or early March.

1999 to 2006: Between 1999 and 2006, patrols were usually conducted twice a day, with the first at approximately 10:00-11:00 $\mathrm{h}$ and the second at 15:00-17:00 h. Often, patrols were timed to coincide with high tide, as the wardens believed this was the turtles' preferred time of emergence to avoid the rocky areas that become exposed during low tide. A complete patrol involved a full circuit of each of the 4 beaches on the island and varied in duration from $30 \mathrm{~min}$ to $3 \mathrm{~h}$, depending on the number of turtles and tracks encountered. Encounters were defined as both a direct turtle sighting and indirect evidence of recent nesting, e.g. tracks where turtles had already emerged and returned to the water. A sighting refers only to interception of turtles.

For a variety of reasons patrols were missed for 1 or more days, and on occasions, the data were not clear about whether there were no patrols or no encounters, which adds to the variance in survey results over time. The extent of the problem varied between seasons but was worse during 2000-2001 and 2005-2006. During peak season (November to December; $61 \mathrm{~d}$ ), when emergences can be expected each day, there were on average $14 \mathrm{~d}(\mathrm{SD}=11.17$; range $=4$ to 31$)$ with either no encounters or no patrols. For the first 7 seasons, from the day of the first encounter to the last encounter, the mean encounter rate was $2.15 \mathrm{~d}^{-1}$. Whilst this might be slightly lower than the true number, assuming that some emergences failed to be recorded, it indicates a small number of encounters per day and therefore a lower degree of error in the Poisson model, from the odd missed patrol. Furthermore, on most occasions when patrols were missed, tracks would have been encountered during subsequent patrols, and thus the emergence would have still been recorded.

For both turtle and track encounters, the date and time the turtle or track was found and the beach location were recorded. For each emergence, the number of nesting attempts made by the turtle was recorded together with whether eggs were laid. On occasions when the turtle was not sighted, the patrol determined whether the turtle had laid eggs based on features such as the appearance of the disturbed sand, but no attempt was made to verify the existence of nests containing eggs.

When turtles were seen, both front flippers were checked for tags. If not tagged, titanium cow ear tags with a unique identification number were fitted to each front flipper either during nesting or immediately after the last egg was laid. Tags were also replaced if there was evidence from tag scars that these had been lost or damaged. Between 2004 and 2006, there was a shortage of tags; therefore many, but not all, untagged turtles remained untagged during those 2 seasons.

2006 to 2008: From 2006 onwards, the monitoring programme was intensified in order to intercept a greater proportion of turtles and to obtain more accurate data on population size. The number of patrols carried out daily was determined by the number of turtles emerging during each part of the season, with fewer patrols being carried out at the beginning and end of the season when fewer turtles were emerging. The monitoring methods followed those used in previous seasons; however, turtle monitoring commenced at 06:00 $\mathrm{h}$ to catch the first emerging turtles of the day and to record any tracks missed from the previous night, and the last patrol began at 18:00 h. During the peak of turtle nesting, between mid-October and the end of January, 7 patrols per day were carried out, at 2-hourly intervals.

Data analysis. With the available data, it was not possible to quantify monitoring effort precisely for each season from 1999 to 2006, but there was variation between seasons (Table 1). Data on total numbers of turtles sighted were therefore not a reliable guide to breeding numbers. Some patrols did not visit the whole island, and no data were recorded for patrols that encountered no turtles. We therefore could not determine measures of turtles encountered per unit effort. With the exception of 2004 to 2006, during which there was a shortage of tags, the majority of turtles encountered were tagged. Furthermore, Limpus (1992) predicted that the probability of titanium tag loss from both front flippers is low (probability of 0.194 for 1 flipper after $5 \mathrm{yr}$ and thus 0.038 for both flippers), so the probability of both tags being lost within a single season should be negligible. On Cousin Island, individual lost tags were replaced as necessary, with 4 to 14 tags replaced annually between 1999 and 2009. No turtles appeared to have lost tags from both flippers. Therefore, to overcome the above difficulties, we assumed that all females that nested on Cousin in a particular season had equal probability of being sighted versus not sighted. If this was the case, the number of times that an individual was sighted in a 
Table 1. Eretmochelys imbricata. Annual summary of hawksbill turtle monitoring data collected on Cousin Island from 1999 to 2009. 'Observations' refers to encounters in which nesting turtles were actually seen

\begin{tabular}{|lccccccc|}
\hline Season & $\begin{array}{c}\text { No. of days with } \\
\text { encounters }\end{array}$ & $\begin{array}{c}\text { Total no. of } \\
\text { encounters }\end{array}$ & $\begin{array}{c}\text { Observations } \\
(\%)\end{array}$ & $\begin{array}{c}\text { Estimated total } \\
\text { no. of clutches }\end{array}$ & $\begin{array}{c}\text { Total no. } \\
\text { tagged }\end{array}$ & $\begin{array}{c}\text { Probability of turtle } \\
\text { not being seen }\end{array}$ & $\begin{array}{c}\text { Actual no. of } \\
\text { turtles (Poisson) }\end{array}$ \\
\hline $1999-2000$ & 97 & 189 & 85 & 123 & 90 & 0.165 & 108 \\
$2000-2001$ & 67 & 128 & 89 & 110 & 71 & 0.215 & 90 \\
$2001-2002$ & 101 & 330 & 50 & 236 & 98 & 0.212 & 124 \\
$2002-2003$ & 121 & 524 & 42 & 395 & 126 & 0.209 & 159 \\
$2003-2004$ & 133 & 593 & 53 & 353 & 132 & 0.136 & 117 \\
$2004-2005$ & 120 & 610 & 35 & 357 & 94 & 0.216 & 124 \\
$2005-2006$ & 100 & 419 & 39 & 331 & 87 & 0.295 & 226 \\
$2006-2007$ & 167 & 1414 & 59 & 662 & 220 & 0.026 & 256 \\
$2007-2008$ & 163 & 1414 & 58 & 775 & 247 & 0.045 & 240 \\
$2008-2009$ & 134 & 1247 & 63 & 654 & 229 & 0.046 & \\
\hline
\end{tabular}

season would follow a Poisson distribution. For individuals that were sighted at least once, the number of times each individual was sighted in a season was determined from tagging records. If the number of times that an individual was sighted $(\mathrm{N})$ is Poisson distributed, then the probability of an individual being sighted $k$ times is given by:

$$
\mathrm{P}(\mathrm{N}=k)=\frac{e^{-\lambda}(\lambda)^{k}}{k !}
$$

where $\lambda$ is the mean number of times that an individual was sighted (including those individuals present, but not sighted). $\lambda$ can be estimated by finding the value that maximises the log-likelihood function, given by:

$$
L(\lambda)=\sum_{k=1}^{k_{\max }} f_{k} \ln \frac{\mathrm{e}^{-\lambda}(\lambda)^{k}}{k !}
$$

where $f_{k}$ is the frequency of individuals sighted $k$ times, and $k_{\max }$ is the maximum number of times an individual was sighted. The summation would normally include $k=0$, but as we do not know how many individuals were not sighted, the summation begins at $k=1$. For each season's data, the value of $\lambda$ that maximised the log likelihood was calculated in Mathematica v. 4.1 (Wolfram). This allowed us to estimate the probability of an individual being present but not sighted in that season, and the probability of an individual being sighted at least once using Eq. (1). These values were then used to calculate the total number of breeding females for each season.

The Seychelles tagging data (E. Talma unpubl. data) and the inventory of all turtles encountered and/or tagged on Cousine Island, $2 \mathrm{~km}$ away from Cousin Island (K. Jolliffe unpubl. data), were used to examine the extent to which hawksbill nest site fidelity encompasses nesting beaches on nearby islands. Mann Whitney $U$-tests were used to compare numbers of nests laid on Cousin and Cousine Islands for those turtles using both islands within 1 season.

\section{RESULTS}

\section{Population trends}

The large increase in the total number of encounters and number of different individuals seen between 2005-2006 and 2006-2007, as shown in Table 1, is indicative of increased monitoring effort during the last 3 seasons (2006 to 2009) rather than an actual increase in population numbers. The probabilities of any individual turtle not being intercepted and recorded at least once within a season were used to estimate the actual number of turtles breeding on Cousin Island in each season (Table 1). Over the 7 yr period from 1999 to 2006 , nesting turtles were observed on average in $56 \%$ of encounters, and analysis indicated that the chances of an individual tagged turtle being sighted at least once within a single season between 1999 and 2006 were high (mean: $79 \%$ ). From 2006 to 2009, turtles were observed in an average of $60 \%$ of all encounters, and the Poisson distribution analysis indicated that $<5 \%$ of all nesting females were missed.

The number of hawksbill turtles nesting on Cousin Island increased significantly in the last 10 seasons, from 1999 to 2009 (correlation $\mathrm{r}=0.836, \mathrm{p}=0.003, \mathrm{n}=$ 10), despite a slight decline in nesting numbers between 2004 and 2006. The probabilities of unseen females as generated by the Poisson distribution allow us to calculate that 226, 256 and 240 female turtles nested annually in the last 3 seasons, respectively, equating to an 8-fold increase in the number of nesting turtles each season since monitoring and protection began in 1970 (Fig. 2). Due to intensive monitoring and robust data for the earliest and latest seasons of monitoring, this 8fold increase is a true indication of the growth of the female nesting population, despite less intensive monitoring during the intervening seasons. A total of 800 different hawksbill turtles were identified by their tag numbers during this 10 yr period. 


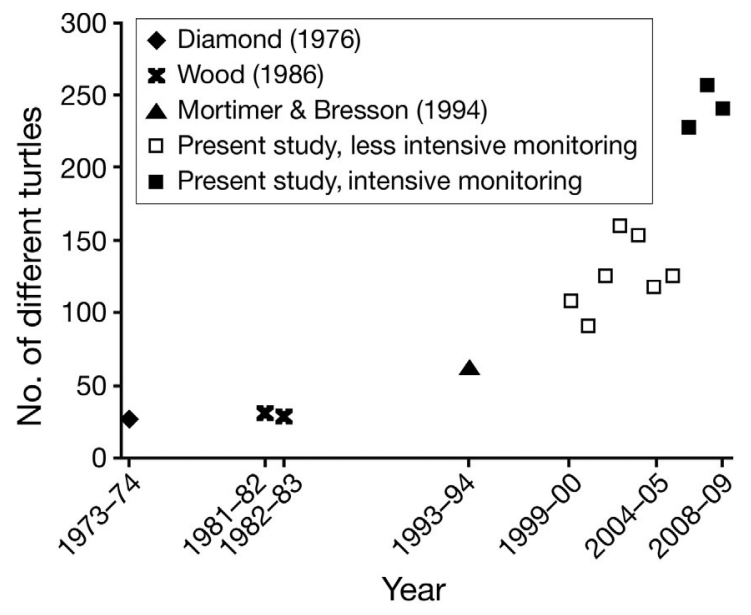

Fig. 2. Eretmochelys imbricata. Estimated numbers of hawksbill turtles nesting annually on Cousin Island between 1973 and 2009

\section{Inter-island nesting and mean nest numbers}

From 2006 to 2009, at least $67 \%$ of all females emerging onto Cousin Island nested multiple times. The number of recorded nestings per turtle ranged from 0 to 7 , with a mean of 2.4 nests per turtle. However, this is only an estimate of the minimum mean number of times a turtle nests within a season, as there is evidence of inter-island nesting between Cousin and its adjacent island, Cousine. The mean number of nests per turtle per season rose to 2.6 when including those nests laid on Cousine.

Tag returns from 2006 to 2009 indicated that a total of 114 turtles that were originally tagged on Cousine came to Cousin to nest during the $3 \mathrm{yr}$ period. The inventory of all turtles encountered on Cousine (K. Jolliffe unpubl. data) identified 60 turtles that were originally tagged on Cousin but subsequently went to Cousine to nest. Furthermore, a proportion of these turtles nested on both islands within 1 season (Table 2). Around 45 to 65 females nest on Cousine each season (K. Jolliffe unpubl. data). Between 2006 and 2009, an

Table 2. Eretmochelys imbricata. Numbers of turtles originally tagged on Cousin or Cousine Islands that also used their neighbouring island for nesting in the same season between 2006 and 2009

\begin{tabular}{|ccccc|}
\hline Season & $\begin{array}{c}\text { Total no. from } \\
\text { Cousine nesting } \\
\text { on Cousin }\end{array}$ & $\begin{array}{c}\text { No. (\%) } \\
\text { nesting on } \\
\text { Cousine in } \\
\text { same season }\end{array}$ & $\begin{array}{c}\text { Total no. from } \\
\text { Cousin nesting } \\
\text { on Cousine }\end{array}$ & $\begin{array}{c}\text { No. (\%) } \\
\text { nesting on } \\
\text { Cousin in } \\
\text { same season }\end{array}$ \\
\hline $2006-2007$ & 37 & $16(43)$ & 23 & $19(83)$ \\
$2007-2008$ & 58 & $15(26)$ & 20 & $20(100)$ \\
$2008-2009$ & 19 & $2(11)$ & 17 & $14(82)$ \\
\hline
\end{tabular}

average of $70 \%$ of the turtles nesting on Cousine also nested on Cousin within the same season, and an average of $7 \%$ of turtles nesting on Cousin also nested on Cousine within the same season. Furthermore, turtles tagged on Cousin in an earlier season were shown to have nested significantly more times on Cousin than on Cousine (Mann Whitney $U=108.0, \mathrm{n}_{1}=\mathrm{n}_{2}=20$, $\mathrm{p}<$ 0.05). This also applied to turtles newly tagged on Cousin between 2006 and 2009 (Mann Whitney $U=$ $303.0, \mathrm{n}_{1}=\mathrm{n}_{2}=33, \mathrm{p}=0.00$ ), or to those newly tagged on Cousine between 2006 and 2009 (Mann Whitney $\left.U=306.5, \mathrm{n}_{1}=\mathrm{n}_{2}=30, \mathrm{p}<0.05\right)$. Turtles that were tagged on Cousine in an earlier season showed no significant preference for nesting on either island (Mann Whitney $U=254.5, \mathrm{n}_{1}=\mathrm{n}_{2}=23, \mathrm{p}>0.05$ ).

It is also known that turtles from Cousin occasionally nest on other islands within the Seychelles, and information from the Seychelles tagging records (E. Talma unpubl. data) indicated that a small proportion of those turtles nesting on Cousin were originally tagged on other granitic islands such as Mahe, Praslin, Aride and Curieuse, as well as other outer islands.

\section{DISCUSSION}

Between 1970 and 1983, during which monitoring intensity was high, the breeding population was estimated to consist of 23 to 30 turtles per season (Diamond 1976, Wood 1986), and the 8-fold increase to the present day confirms the success of the management strategy. Fig. 2 shows a positive exponential increase in nesting females since monitoring began, with an average increase of 16.5 turtles per season; however, this curve could be partly due to less intensive monitoring during some of the intervening seasons. It is possible that the decline in numbers of nesting females between 2004 and 2006 was partly due to disruption caused by the tsunami in December 2004, when a large amount of sand was washed off the beach. Following this, local wardens observed fewer turtles in the water, and breeding numbers were $25 \%$ lower in 2004- 2005 than in the previous breeding season, although natural fluctuations in breeding numbers could also account for variations. Sand on the beach has since been restored, and the breeding population size remains high. At least 800 turtles have used Cousin Island as a nesting site in the last $10 \mathrm{yr}$, with each season bringing untagged and thus previously unseen turtles as well as tagged turtles migrating from other islands. Evidence for positive population trends such as this are 
emerging at other long-term hawksbill turtle monitoring sites around the world, such as Barbados, West Indies (Beggs et al. 2007), and the Yucatan Peninsula, Mexico (Garduño-Andrade et al. 1999), and demonstrates the success of the protective conservation actions taken.

The minimum mean number of nests per turtle per season on Cousin Island (2.4) was slightly lower than the mean of 3.1 found by Mortimer \& Bresson (1999). However, evidence of inter-island nesting has been reported previously for the Seychelles hawksbill population by Hitchins et al. (2003), and this was confirmed by the frequent within-season nesting migrations of turtles between the neighbouring islands of Cousin and Cousine. It is possible that the frequency of interisland nesting is increasing, thus lowering the mean number of clutches laid on 1 island, and this warrants further investigation. Analysis indicates that for some turtles nesting on both Cousin and Cousine Islands, there may be a preference for nesting on Cousin.

Although monitoring effort between 1999 and 2006 was low with some data missing, an indication of nesting numbers could still be calculated. While this method made various assumptions that should perhaps be treated with caution, intensive data from 2006 to 2009 supported the findings for the earlier period, indicating that some monitoring was better than none at all. Furthermore, analysis indicated that fewer than $5 \%$ of turtles were missed during the last 3 seasons. It would be beneficial for future research to focus on the inter-island breeding patterns of these females across the entire Seychelles archipelago to determine how far they roam and how many islands they may use within 1 nesting season.

Acknowledgements. We thank Nature Seychelles and the staff who made this research possible. Particular thanks go to J. Hardcastle and R. Bristol for their guidance and support both in the Seychelles and subsequently. We also thank A. Perriol for data entry and G. Simeon, N. Bunbury, N. Doak, D. Evans, F. Hobro and I. Paynter, who assisted in various ways during this research. We thank E. Blais, G. Simeon, I. Valmont and all the wardens on Cousin Island who were involved in data collection during this period. We also thank E. Talma from the Marine Conservation Society, Seychelles, and K. Jolliffe from Cousine Island respectively for kindly providing the inventory of all turtle tags used in the Seychelles and all turtles encountered on Cousine Island. Finally, we thank all the reviewers for their valuable input. The research was supported by a Natural Environment Research Council studentship to Z.C.A. (NER/S/M/2005/13297), the Sir Philip Reckitt Educational Trust and the School of Biological Sciences at the University of East Anglia.

\section{LITERATURE CITED}

Beggs JA, Horrocks JA, Krueger BH (2007) Increase in hawksbill sea turtle Eretmochelys imbricata nesting in
Barbados, West Indies. Endang Species Res 3:159-168

Diamond AW (1976) Breeding biology and conservation of hawksbill turtles, Eretmochelys imbricata, on Cousin Island, Seychelles. Biol Conserv 9:199-215

Garduño-Andrade M, Guzman V, Miranda E, BrisenoDuenas R, Abreu-Grobois FA (1999) Increases in hawksbill turtle (Eretmochelys imbricata) nestings in the Yucatan Peninsula, Mexico, 1977-1996. Chelonian Conserv Biol 3:286-295

Hill MJ, Vel TM, Holm KJ, Parr SJ, Shah NJ (2002) Biodiversity surveys and conservation potential of inner Seychelles Islands. In: Hill MJ (ed) Atoll research bulletin. National Museum of Natural History, Smithsonian Institution, Washington, DC, p 49-57

Hitchins PM, Bourquin O, Hitchins S (2003) Interisland nesting by hawksbill turtles (Eretmochelys imbricata) in Seychelles. Phelsuma 11:70-71

Limpus CJ (1992) Estimation of tag loss in marine turtle research. Wildl Res 19:457-469

Meylan AB, Donnelly M (1999) Status justification for listing the hawksbill turtle (Eretmochelys imbricata) as critically endangered on the 1996 IUCN Red List of Threatened Animals. Chelonian Conserv Biol 3:200-224

Mortimer JA (1984) Marine turtles in the Republic of the Seychelles: status and management. IUCN, Gland

Mortimer JA (1996) Identifying and addressing sea turtle conservation and management priorities. In: Humphrey SL, Salm RV (eds) Status of sea turtle conservation in the western Indian Ocean. UNEP Regional Seas Reports and Studies No. 165. IUCN/United Nations Environment Programme, Nairobi, p 11-14

Mortimer JA (2000) Sea turtle conservation programmes: factors determining success or failure. In: Salm RV, Clark JR, Siirila E (eds) Marine and coastal protected areas: a guide for planners and managers. IUCN, Washington, DC, p 327-333

Mortimer JA, Balazs GH (1999) Post-nesting migrations of hawksbill turtles in the granitic Seychelles and implications for conservation. In: Kalb H, Wibbels TI (compilers) Proc 19th Annu Symp Sea Turtle Biol Conserv. NOAA Tech Memo NMFS-SEFSC-443, p 22-26

Mortimer JA, Bresson R (1994) The hawksbill nesting population at Cousin Island, Republic of Seychelles: 1971-72 to 1991-92. In: Shroader BA, Witherington BE (compilers) Proc 13th Annu Symp Sea Turtle Biol Conserv. NOAA Tech Memo NMFS-SEFSC-341, p 115-117

Mortimer JA, Bresson R (1999) Temporal distribution and periodicity in hawksbill turtles (Eretmochelys imbricata) nesting at Cousin Island, Republic of Seychelles, 19711997. Chelonian Conserv Biol 1999 3:318-325

Mortimer JA, Collie J (1998) Status and conservation of sea turtles in the Republic of Seychelles. In: Epperly SE, Braun J (compilers). Proc 17th Annu Sea Turtle Symp. NOAA Tech Memo NMFS-SEFSC-415, p 74-75

Mortimer JA, Donnelly M (2008) Eretmochelys imbricata. In: IUCN 2010. IUCN Red List of Threatened Species. Version 2010.1. www.iucnredlist.org (accessed on 22 April 2010)

Taylor JD (1968) Coral reef and associated invertebrate communities around Mahe, Seychelles. Philos Trans R Soc Lond B Biol Sci 254:129-206

$>$ Wood VE (1986) Breeding success of hawksbill turtles Eretmochelys imbricata at Cousin Island, Seychelles and the implications for their conservation. Biol Conserv 37: 321-332 